\title{
IMPLEMENTATION OF GEOGRAPHIC INFORMATION SYSTEM TECHNOLOGY IN MAIL DELIVERIES ORGANIZATION
}

\author{
Vladimir Janko Desnica* \\ Public Enterprises of PTT, Novi Sad, Serbia \\ Dr Dragana Šarac \\ University of Novi Sad, Faculty of tehnical science, Novi Sad, Serbia
}

The Post of Serbia should create conditions for improvement of its assortment of services by innovations of the current services and introduction of new commercial services in the work process. This can be achieved if high technologies - automation, mechanization and particularly informationcommunication technology and Geographic Information System (GIS) are introduced. The paper discusses results of the case study which comprises application of GIS on the example of delivery areas of the Post of Serbia in Novi Sad based on created thematic maps. The aim is to increase efficiency and productivity of delivery services by application of this technology.

Key words: Delivery service, Geographic information system (GIS), Thematic maps

\section{INTRODUCTION}

Geographic information system (GIS) is a technological field that incorporates geographical features with tabular data in order to map, analyze, and assess real-world problems [12]. Almost every human activity relative to a territory or the whole planet may be improved by application of optimized geographic information system. GIS is used in business, scientific and public projects. It is considered as a dominant tool which provides effective planning, analyzing and managing, from the cartography itself, which is a base for GIS development, all along to business, public and military systems. It is used in all fields which use spatial i.e. geographic data (for scientific research, management of resources, property management, development planning, infrastructural planning, in electrical, machine and civil construction industries, architecture, banking, economics, urban planning, transport, health care system, tourism, for marketing research, geology, ...). GIS is used on the global as well as on the local level (e.g. national atlas of a country (cities, population, telephone area codes, postal codes), hydrography of a country (rivers, lakes), infrastructure (hospitals, schools, parks, cemeteries, museums), transport (airports, roads and highways, rivers, railroads), education, entrepreneurship, etc.) $[02,11,13]$.
GIS in Serbia is mainly used in the following areas: traffic and transport, telecommunications, tourism, city infrastructure (water pipelines, heating system, gas pipelines), education, local selfgovernment [03, 07].

The topic of the paper is improvement of the situation in the Post of Serbia, especially its delivery services, as well as providing an effective work and optimal use of working hours of post deliverers by application of GIS technology.

\section{NEW TECHNOLOGIES IN THE POST OF SERBIA}

A state company for offering postal services "Srbija" (JP PTT "Srbija") is the oldest, the most powerful and the widest available infrastructural system in the country. The Post of Serbia is a company which offers postal services including carrying various kinds of mail from a sender to an addressee, so the mail delivery service plays an important part in the system.

The notion of mail transport signifies a continuous manner of transferring mail in all phases of a unique technological process. A unique technological process which comprises all interdependent phases of transfer makes up a completed production cycle. A production cycle in mail transport is made up of 5 phases: reception, dispatch, transport, arrival and delivery [05]. 
It is very important to deliver mail quickly, properly and safely. In order to achieve this, it is necessary to organize the work of the mail delivery service in such a way that it satisfies the requirements of the market and the needs of the customers and to work in a cost-effective way, i.e. to make profit [01].

Facing a competition which is getting more and more powerful, the Post of Serbia should maintain its rightful position of the national leader and one of the regional leaders in the modern market of postal services by innovations of the current services and introduction of new commercial services. Replacement of out-of-date technology and introduction of high technology (automation, mechanization and particularly information-communication technology and GIS) in the work process create conditions for improvement of assortment of services.

In the first place reengineering in the delivery process means the process of innovation, or in other words, it provides the delivery process innovations by use of modern technical solutions (introduction of modern equipment and facilities, application of Postal Address Code (PAC) and especially GIS). GIS has proved its advantages where visualization of spatial data is required as well as manipulation with a large number of data. It is quite certain that wider application of GIS technology in the Post of Serbia will confirm its advantages.

\section{Organization of mail delivery}

Mail delivery to addressees is a final phase of a single technological process. Regarding the manner of mail delivery, two organizational systems can be distinguished:

- mail delivery to home or business premises addresses of an addressee,

- mail delivery in the post office through PO box service and delivery counters.

Delivery is certainly the most expensive process in postal technology; hence it is quite understandable to try to reduce the expenses [6]. Possibilities to reduce delivery expenses are numerous, only an effective tool is required to find the most efficient solution to this problem. More intensive application of GIS proves that this technology is one of the most efficient solutions regarding more qualitative delivery organization.

\section{APPLICATION OF GIS IN THE PROCESS OF DELIVERY ORGANIZATION}

In order to analyze territorial availability of postal services to citizens, rationalization of transport and delivery of postal items, the Post of Serbia bas been developing Geographic information system - GIS since 2002.

Based on the information about addresses where the postmen deliver the mail, the Post of Serbia has positioned on the map (geo-referenced) about 1 million of house numbers in all major cities in Serbia.

Based on the data from Geographic information system, the Post of Serbia is able to conduct the following analyses:

- analysis of territorial access to facilities and users,

- planning the distribution of advertising material,

- route planning,

- generation of address lists by zones,

- analysis of population density in order to plan the capacity of infrastructure or

- selection of the best locations for opening new facilities and others [14].

The most important segment of GIS is geographic information. It comprises spatial, time and attribute components. Each of these components can be changed, which affects the manner and selection of analysis, storage and presentation of information itself. Every variable, i.e. information which may be located spatially, can be integrated in GIS.

Development of GIS and introduction of PAC help meet the conditions for application of this technology in the Post of Serbia, particularly in delivery organization [9]. PAC is a new way of addressing mail in Serbia and is made up of six digits written beside the city or town name. This code helps describe the territory of Serbia, i.e. a series of digits replaced the name of municipality, part of the city and street (or its part). Writing the PAC ensures unmistakable dispatch and delivery of mail to the recipients. The software package Maplnfo is used for work with Geographic Information System in the Post of Serbia. The main prerequisite for creation of qualitative and usable vector maps is a good and detailed base. 
The base for this creation may be a detailed aerial photo (orthophoto) or a satellite image.

Spatial data are first collected and stored in relational databases, i.e. a connection between geodata and relational databases is generated. Files created to write geometric elements in a binary form in them are used to describe spatial data.

The first step in database creation in the Post of Serbia is inserting the streets i.e. street network and assigning a code. Drawing in the complete street network is followed by drawing in objects (houses, buildings, industrial facilities). Each object is assigned a street code which contains house number. There follows data pairing which involves available data with the assigned codes. Microsoft Office Access which is compatible with Maplnfo software is used for application of data from databases [08].

GIS is more and more used in automated vehicle control (AVC). The vehicles contain a built-in Global Positioning System- GPS so the vehicle fleet may be controlled in real time thus providing security of both deliverer and the vehicle [10]. Fuel filling and consumption can be also controlled along with departure time and stops, opening and closing of the doors, etc. Vehicle movement is possible to control in earlier period as well and this enables analyses and control of accuracy and quality of deliverer's work. It is also possible to control a mailman in his delivery area by means of personalized locators. For the purpose of further improvement of delivery quality a greater use of personalized locators for mailmen is necessary. Their use contributes to security of mailmen in the first place (because the alarm is activated in case of emergency) while the control of movements of mailmen in a particular area provides and improves quality of delivery. Application of GIS technology in past time and real time helps to establish if the movements are appropriate or certain corrections are possible to make.

\section{Analysis of productivities of delivery areas based on thematic maps - case study}

When organizing the delivery the following basic elements for formation of delivery areas must be considered: number of users (legal entities and physical persons), quantity and type of mails and distance traveled by a mailman in the area. Application of GIS and creation of thematic maps offer quickly obtained data about the way of delivery organization in a delivery area or a city.

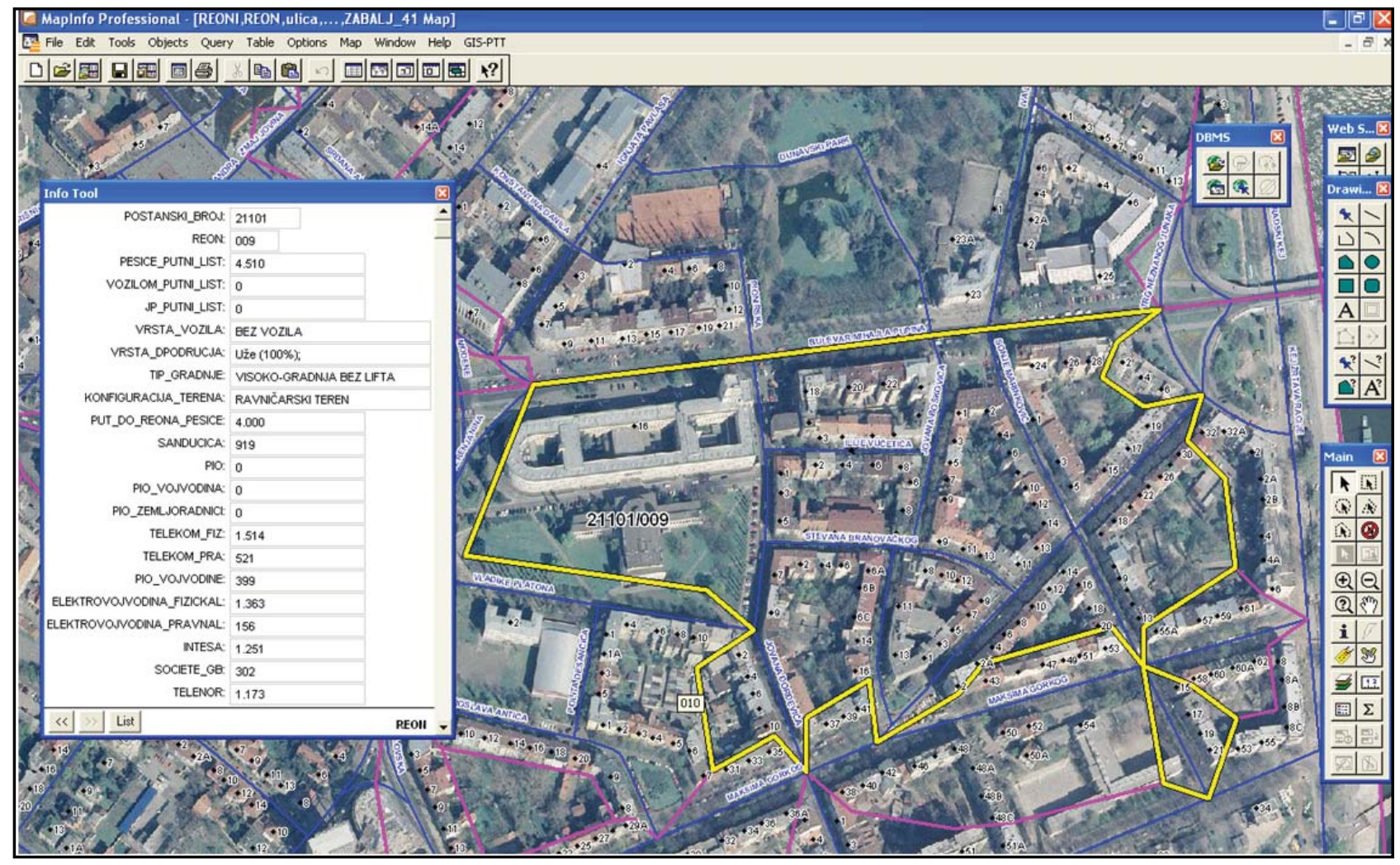

Figure 1: Thematic map with the data: delivery mail area (21101, 009), distance traveled by a mailman in a delivery area (4510 meters), number of households (919), number of telephone bills for physical persons and legal entities (1514 and 521), number of pensioners (399), number of electricity bills for physical persons and legal entities (136 and 156), number of bank reports (1251and 302), number of mobile operators bills (1173) 
Thematic maps provide an overview of delivery capacity for a specific segment, delivery area and for the whole company. In working unit Novi Sad GIS technology is used in the mail delivery phase in order to equal productivities of areas in the Post of Serbia. A thematic map which is created contains all necessary and relevant data for delivery organization, such as: population number, number of households, number of unregistered mails for a particular period, distance traveled by a mailman in a particular delivery area, optimal number of post offices for a particular area, number of telephone bills, number of mobile operators bills, number of electricity bills, total number and amount of pensions, number of legal entities, and so on. If a particular area is selected, the requested data are quickly given, which is shown in figure 1.

In earlier period it was necessary to spend a large number of working hours to collect these data, which involved physical counting of household, legal entities and mails in a particular area. A great difference in numbers of household and legal entities in areas was established based on thematic maps and their analysis. Selection of specific postal address codes quickly offered the requested data so it was possible to establish which segments could be transferred from one (more productive) area to the neighboring (less productive) area. Thus productivities of areas were balanced (by number of households and of legal entities and by distance traveled by a mailman in the area). Moreover, only measuring distance traveled by a mailman in an area required at least 5 measurements (by bicycle or moped) in order to establish the average distance traveled by a mailman [01].

\section{RESULTS AND DISCUSSION}

A very important step in database creation and creation of entire GIS is data collection phase. Preciseness and exactness is especially underlined in this phase because mistakes in measurements, input and data classification may produce completely wrong results and consequently wrong analyses and models in further phases. Variety of information which enters the database is great because all entered data are spatial reference information and location reference information.

In the Post of Serbia GIS has even greater application in organization of letter delivery, parcel delivery and specialized delivery, mail delivery, desk operations, timetable and transport optimization. Using the data and thematic maps which GIS offers, the delivery operator can analyze the obtained data and very quickly make decisions about possible changes for the purpose of optimization of delivery organization: organizer may decide whether to transfer one segment from one delivery area to another, or to transfer one part of the city to a delivery area of another delivery post office. All data from the thematic map in figure 1 are immediately available for delivery organization in working unit Novi Sad for 263 delivery areas (including district of South Bačka in AP of Vojvodina). It used to take several working days to obtain these data.

Application of GIS technology on the concrete example shows that analysis is performed in a faster, more qualitative and cheaper way while the results are immediately visible. It provides improvement in efficiency and delivery, more qualitative definition of expenses, fuel consumption control and more effective organization; on the other hand, it reduces unproductive walk of mailmen.

\section{CONCLUSION}

The tendencies of the future development of the post office should be based on spreading and modernizing, introducing new technologies in compliance with general development in Europe and the world.

It could be said that the Post of Serbia has found in GIS a suitable engineering tool which provides a qualitative work that can be performed in the office and which improves post offices organization and desks work organization, transport and processing as well as delivery.

The Post of Serbia must timely respond to a challenge of increasing competition and introduce GIS in the system of delivery organization, but also in the system of strategic decision-making in general if it wants to remain the leader in its work.

Since in the Post of Serbia all relevant postal capacities such as PAC, regular delivery (areas, mailboxes, depots, mailmen stations), specialized delivery, timetable, reception and delivery are georeferenced, more intensive application of GIS technology is the main prerequisite to advance the process and improve quality in all phases of production cycle, in other words, from mail reception, dispatch, transport and arrival to 
analyses and define priorities in a more qualitative way as well as to provide more effective and faster decision-making. Application of GIS technology in the process of delivery organization ensures significant increase in productivity, more effective use of working hours and more qualitative services and overall operations of the organization.

\section{REFERENCES}

1) Desnica,V., Šarac, D., (2012) Application of new technologies in the Post of Serbia in function of efficient business, II International Symposium Engineering Management and Competitiveness 2012 (EMC 2012), Zrenjanin, 108-112.

2) Gerasimović, M., Stanojević, Lj., Veljović, A., Cvijović, N., (2010) Application of geographic information systems technology in entrepreneurship education, Annals of faculty engineering Hunedoara - International journal of engineering, 8( 2), 197-200.

3) Grgurović, B, Štrbac, S, Popović, M., (2010) Positioning in the market of commercial services the postal activities, International Scientific Conference Management 2010., Krusevac, Serbia, 554-560.

4) Janković, D., Milidragović, R., (2011) Model for improving spatial planning area managment in local government implementation of GIS technology, Annals of faculty engineering Hunedoara - International journal of engineering, 9 (1), 43-52.

5) Kujačić, M., (2005.) Postal traffic, Novi Sad: Faculty of technical sciences
6) Marković, Z., (2009) Automated processing centers - prerequisite for postal services business processes re-engineering, PosTel 2009, Beograd, 185-194.

7) Marković, Z., Ostojić, Lj., (2006) Ptt route software for designing of transport vehicles route and creation of timetables used in transport of postal items, PosTel 2006, Beograd, 243-252.

8) Nedeljković, S., (2005) Application of GIS technology in delivery organization, Modern Post, no. 3, 55-60.

9) Ostojić, Lj., (2004) Application of GIS technology in postal traffic, Postfest, Beograd.

10) Stanković, S., Tadić, Z., Vasković, V., Ljubojević, M. (2010):The application of the ICT on optimization of traffic currencies and fluency of public city transport system", Journal of Applied Engineering Science, Vol. 8, No. 1, pp. 27-32

11) Zahorjanski, M., Veljović, A., (2011) Use of analytical data bases and gis for monitoring performance of institutions of higher education, Journal Metalurgia international, 16 (12), 136-139.

12) www.gislounge.com (Retrieved January, 2013)

13) www.gis.ba (Retrieved December, 2010)

14) www.posta.rs (Retrieved May, 2011)

Paper sent to revision: 24.09.2012.

Paper ready for publication: 06.03.2013. 